\title{
Barium M-type Ferrite as an Electromagnetic Microwave Absorber in the GHz Range
}

\author{
Satoshi Sugimoto*, Katsumi Okayama*†, Sin-ichi Kondo*†, Hiroyasu Ota**, \\ Masafumi Kimura**, Yoshiyuki Yoshida**, Hajime Nakamura*, \\ David Book*, Toshio Kagotani* and Motofumi Homma \\ *Department of Materials Science, Graduate School of Engineering, Tohoku University, \\ Aoba-yama 02, Sendai, 980-8579, Japan \\ ${ }^{* *}$ EMC Lab. Co., Ltd., 6-6-3, Minami-Yoshinari, Aoba-ku, Sendai 980-3204, Japan
}

\begin{abstract}
The electromagnetic microwave absorption properties of Barium M-type ferrite, in which $\mathrm{Fe}^{3+}$ was substituted by $\left(\mathrm{Ti}_{0.5} \mathrm{Mn}_{0.5}\right)^{3+}$, were investigated in the $\mathrm{GHz}$ frequency range. The anisotropy field $\left(H_{\mathrm{A}}\right)$ of Barium M-type ferrite can be changed by varying the $\mathrm{Ti}_{0.5} \mathrm{Mn}_{0.5}$ content, which enables the natural resonance frequency $(f r)$ to be controlled, in the range $48 \mathrm{GHz}$ to $8 \mathrm{GHz}$. $\mathrm{BaFe}_{12-x}\left(\mathrm{Ti}_{0.5} \mathrm{Mn}_{0.5}\right)_{x} \mathrm{O}_{19}$ sintered ferrites with compositions $x=2.5$ to 5 exhibited good microwave absorption properties, with minimum reflection losses (R.L.) less than $-20 \mathrm{~dB}$ in 1 to $20 \mathrm{GHz}$ frequency range, for matching thicknesses $(d m)$ of 0.5 to $3.8 \mathrm{~mm}$. BaFe $\mathrm{Ba}_{12-x}\left(\mathrm{Ti}_{0.5} \mathrm{Mn}_{0.5}\right)_{x} \mathrm{O}_{19}$ ferrite-resin composites with 70 mass $\%$ ferrite, exhibited wide bandwidths with $R . L .<-20 \mathrm{~dB}$. In particular, the composite samples with compositions $x=3$ and $x=4$ had wide bandwidths of 14.1 to $\sim 20 \mathrm{GHz}$ and 7.4 to $12.0 \mathrm{GHz}$, for matching thicknesses of $1.6 \mathrm{~mm}$ and $2.7 \mathrm{~mm}$, respectively. These matching thicknesses were smaller than for conventional spinel ferrites. It may be concluded that Barium M-type ferrite is a good candidate for a thin electromagnetic microwave absorber in the $\mathrm{GHz}$ range. This is the first study to show that it is possible to use the natural resonance of M-type ferrite for the absorption of microwave radiation.
\end{abstract}

(Received April 15, 1998)

Keywords: barium M-type ferrite, electromagnetic wave absorber, substitutional elements, natural resonance, reflection loss, matching thickness, bandwidth

\section{Introduction}

Recently, wireless communication tools such as mobile telephones and computer local area networks (LAN), have become very popular. However, as the number of systems using high frequency electromagnetic waves had increased, serious electromagnetic compatibility (EMC) problems $^{(1)}$ have become apparent. This has led to the search for electromagnetic wave absorption materials for the use in the $\mathrm{GHz}$ range.

Spinel type ferrites, such as NiZn and MnZn ferrites, have been used as electromagnetic wave absorbers in the $\mathrm{MHz}$ range ${ }^{(2)}$. However, these materials do not work well in the $\mathrm{GHz}$ range due to a large decrease in magnetic loss $\left(\mu_{\mathrm{r}}\right)^{(3)(4)}$. Barium ferrites with a magnetoplumbite structure (M-type: $\left.\left(\mathrm{BaFe}_{12} \mathrm{O}_{19}\right)\right)$ exhibit a uniaxial magnetic anisotropy, and so have been used as permanent magnets. The magnetic loss $\left(\mu_{\mathrm{r}}^{\prime \prime}\right)$ of these ferrites increase at the natural resonance frequency, and so we decided to investigate whether electromagnetic wave absorption was possible in the $\mathrm{GHz}$ range. In addition, M-type ferrites have an advantage in that the $\mathrm{Fe}_{2} \mathrm{O}_{3}$ content $(85.7$ at \%) is higher than in conventional spinel ferrites (50 vol\%), which may lead to lower production costs.

It is well known that the natural resonance frequency $(f r)$ is related to the anisotropy field $\left(H_{\mathrm{A}}\right)$ by the expres-

Graduate Student, Tohoku University. sion $2 \pi f r=\gamma H_{\mathrm{A}}$ where $\gamma$ is the gyrometric ratio ${ }^{(5)}$, which would result in a theoretical $f r$ value of $47.6 \mathrm{GHz}$, for $\mathrm{Ba}$ M-type ferrite with a $H_{\mathrm{A}}$ value of $1.36 \mathrm{MA} / \mathrm{m}$ $(17 \mathrm{kOe})^{(6)(7)}$. Many researchers have reported that the $H_{\mathrm{A}}$ of Ba M-type ferrite can be changed by the substitution of $\mathrm{Fe}^{3+(5)(8)-(11)}$ resulting in a shift in $f r$. Therefore one may expect that the electromagnetic wave absorption properties can also be controlled by changing the amount of substitutional elements present. It should be noted, however, that the electromagnetic wave absorption properties are also influenced by the frequency dependence of permeability $\left(\mu_{\mathrm{r}}\right)$ and permittivity $\left(\varepsilon_{\mathrm{r}}\right)^{(12)}$, Therefore, it is important to investigate the effect of substitutional elements on this dependence, in order to use this type of ferrite in electromagnetic wave absorption devices. In this study, Ti and Mn substitutional elements with the ratio $\mathrm{Ti}_{0.5} \mathrm{Mn}_{0.5}$ were chosen, and the electromagnetic wave absorption properties of sintered and resin-composite $\mathrm{BaFe}_{12-x}\left(\mathrm{Ti}_{0.5} \mathrm{Mn}_{0.5}\right)_{x} \mathrm{O}_{19}$ ferrites were investigated.

\section{Experimental Procedure}

Ba M-type ferrites, with compositions $\mathrm{BaFe}_{12-x}$ $\left(\mathrm{Ti}_{0.5} \mathrm{Mn}_{0.5}\right)_{x} \mathrm{O}_{19},(x=0$ to 5$)$, were prepared by conventional powder metallurgy. The starting materials of $\mathrm{BaCO}_{3}, \alpha-\mathrm{Fe}_{2} \mathrm{O}_{3}, \mathrm{TiO}_{2}$ and $\mathrm{MnCO}_{3}$ powders (purity $>99 \%$ ) were mixed in a planetary ball mill and compacted into cylindrical shaped samples. These compacts were crushed into powders of size less than $300 \mu \mathrm{m}$ after calci- 
nation at $1473 \mathrm{~K}$ for $4 \mathrm{~h}$, and then pulverized into fine powders of size less than $1 \mu \mathrm{m}$ using a planetary ball mill. The phases present in these powders were characterized by X-ray diffraction (XRD). These powders were compacted into blocks of size $20 \times 10 \times 10 \mathrm{~mm}^{3}$ with and without a magnetic field of $0.8 \mathrm{MA} / \mathrm{m}$, and then sintered at $1573 \mathrm{~K}$ for $10 \mathrm{~h}$ in air. The composite samples were prepared by crushing these sintered bodies into powders $(<300 \mu \mathrm{m})$ and mixing with an epoxy resin at different ratios from 40 to 80 mass\%.

The magnetic properties were measured using a vibrating sample magnetometer (VSM), with a maximum applied field of $1.2 \mathrm{MA} / \mathrm{m}(15 \mathrm{kOe})$. The magnetization value at the applied field of $1.2 \mathrm{MA} / \mathrm{m}\left(M_{1.2}\right)$ was taken as the saturation magnetization value, and the anisotropy field $\left(H_{\mathrm{A}}\right)$ values were estimated by extrapolating the magnetization curves along the easy and hard axes of aligned samples, and finding the field at which they intersect. The Curie temperature was measured using a magnetic balance. The scattering parameters $\left(S_{11}, S_{21}\right)$ of toroidally shaped sintered ferrites and ferrite-resin composites $\left(\phi_{\text {out }} 7.00 \times \phi_{\text {in }} 3.04 \times 1 \mathrm{~mm}^{3}\right)$, were measured using a Hewlett-Packard HP8510C network analyzer in the frequency range 0.05 to $20.05 \mathrm{GHz}$. These parameters were then used to determine the complex permeability and permittivity. The electromagnetic wave absorption properties were determined from the frequency dependence of reflection losses (R.L.).

\section{Results and Discussions}

Before measuring the magnetic properties and electromagnetic wave absorption properties, the microstructures of the samples were studied by X-ray diffraction to confirm the presence of magnetoplumbite (M) type phase. Figure 1 shows the X-ray diffraction patterns of the $\mathrm{BaFe}_{12-x}\left(\mathrm{Ti}_{0.5} \mathrm{Mn}_{0.5}\right)_{x} \mathrm{O}_{19}$ ( $x=0$ to 5) ferrites sintered at $1573 \mathrm{~K}$ for 10 hours. The samples were almost single phase M-type phase, however, X-ray reflected intensities from other phases were observed in the samples for $x \geqq 5$.

Figure 2 shows the variation of the saturation magnetization $\left(M_{1.2}\right)$, anisotropy field $\left(H_{\mathrm{A}}\right)$ and Curie temperature $\left(T_{\mathrm{c}}\right)$ with respect to $\mathrm{Ti}_{0.5} \mathrm{Mn}_{0.5}$ content $(x)$. The values of $M_{1.2}, H_{\mathrm{A}}$, and $T_{\mathrm{c}}$ decreased with increasing $\mathrm{Ti}_{0.5} \mathrm{Mn}_{0.5}$ content, which is considered to be due to the replacement of $\mathrm{Fe}^{3+}$ by $\left(\mathrm{Ti}_{0.5} \mathrm{Mn}_{0.5}\right)^{3+}$. However, the locations of the sites of the $\mathrm{Ti}^{4+}$ and $\mathrm{Mn}^{2+}$ ions were not investigated in this study. The natural resonance frequencies $(f r)$ were calculated from the $H_{\mathrm{A}}$ values using the formula shown in Fig. 2, and it was found that these $f r$ values decreased from $48 \mathrm{GHz}$ to $8 \mathrm{GHz}$ with increasing $\mathrm{Ti}_{0.5} \mathrm{Mn}_{0.5}$ content. Therefore, it can be said that the $f r$ can be controlled by changing the amount of substitutional elements present in $\mathrm{M}$-type ferrite. The $T_{\mathrm{c}}$ value decreases monotonically, which suggests that the substitutional elements of $\mathrm{Ti}_{0.5} \mathrm{Mn}_{0.5}$ enter the M-type phase.

The complex permeabilities and permittivities of the $\mathrm{BaFe}_{12-x}\left(\mathrm{Ti}_{0.5} \mathrm{Mn}_{0.5}\right)_{x} \mathrm{O}_{19}$ samples were measured using a network analyzer, and the dependence of $\mu_{\mathrm{r}}^{\prime \prime}$ on the fre-

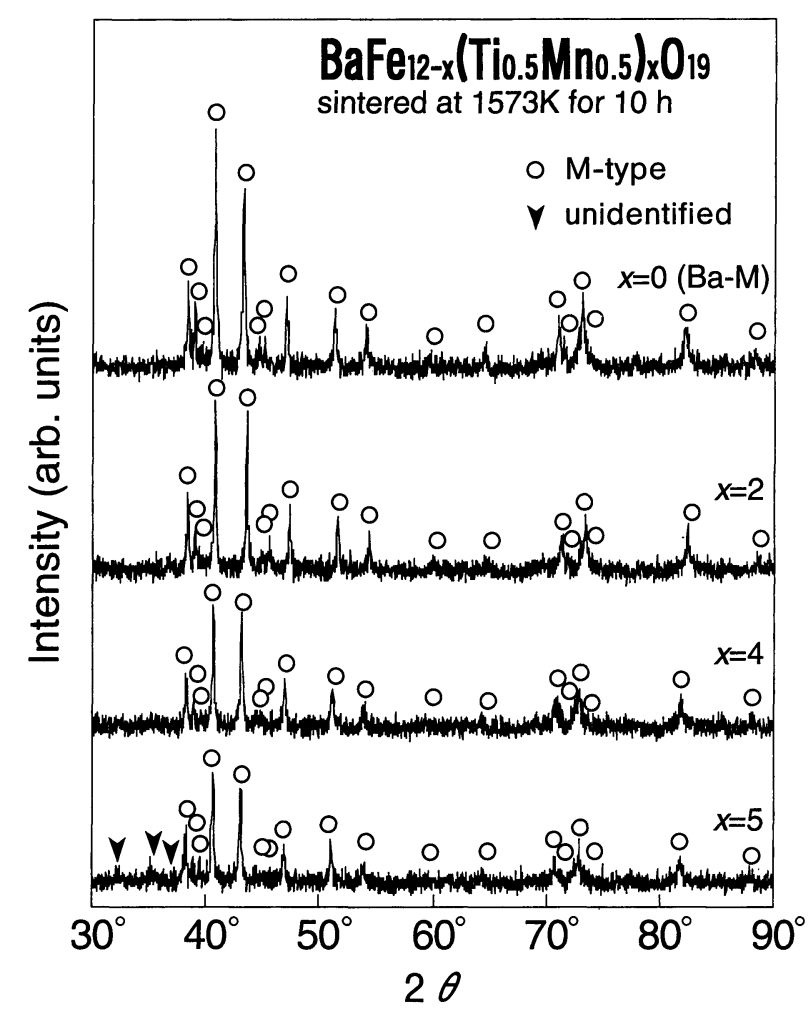

Fig. 1 X-ray diffraction patterns of the $\mathrm{BaFe}_{12-x}\left(\mathrm{Ti}_{0.5} \mathrm{Mn}_{0.5}\right)_{x} \mathrm{O}_{19}$ ferrite sintered at $1573 \mathrm{~K}$ for $10 \mathrm{~h}$.
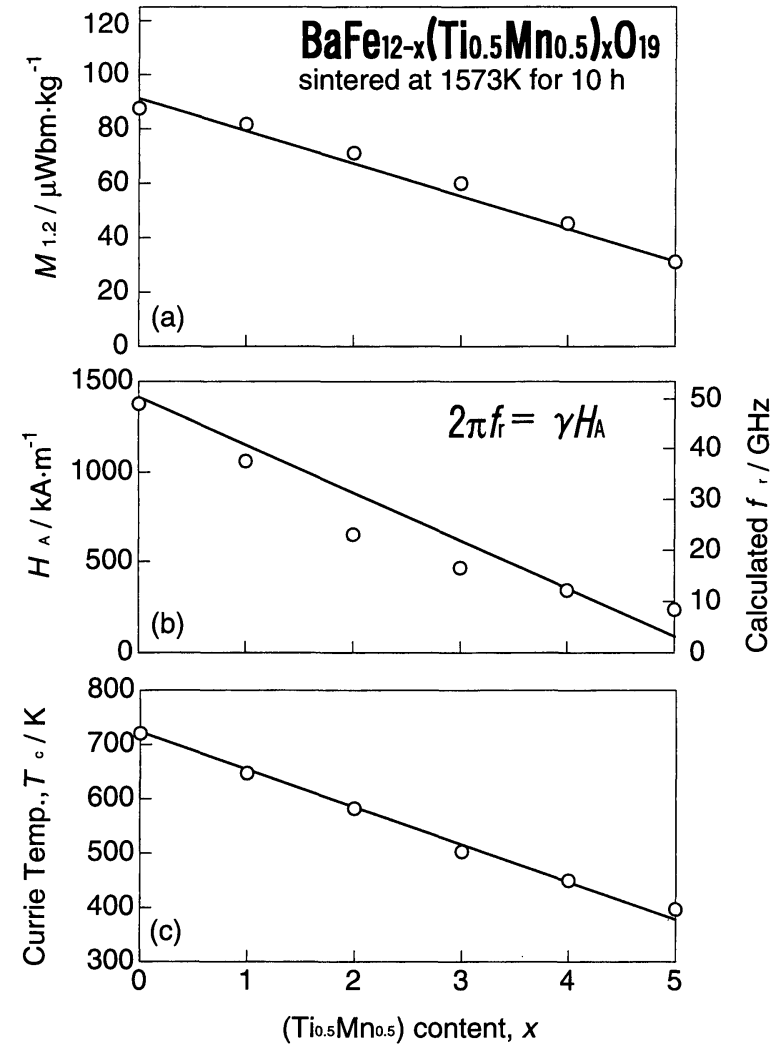

Fig. 2 Variation of the saturation magnetization $\left(M_{1.2}\right)$, anisotropy field $\left(H_{\mathrm{A}}\right)$ and Curie temperature $\left(T_{\mathrm{c}}\right)$, against $\mathrm{Ti}_{0.5} \mathrm{Mn}_{0.5}$ content $(x)$. 
quency is shown in Fig. 3. It can be seen that the natural resonance frequency $(f r)$, which is associated with the frequency of the $\mu_{\mathrm{r}}^{\prime \prime}$ peak decreases from $15.9 \mathrm{GHz}$ to $3.9 \mathrm{GHz}$, with increasing $\mathrm{Ti}_{0.5} \mathrm{Mn}_{0.5}$ content. This decrease in $f r$ agrees well with the $f r$ values estimated from $H_{\mathrm{A}}$ (shown in Fig. 2), except that all the $f r$ values for the measured samples ( $x=2.5$ to 5 ) were lower. This difference may be because at higher $\mathrm{Ti}_{0.5} \mathrm{Mn}_{0.5}$ content, the lower values of $H_{\mathrm{A}}$ (Fig. 2(a)) reduce the effect of the magnetic field on the alignment of the powders during pressing. The peak values of $\mu_{\mathrm{r}}^{\prime \prime}$ also changed with $\mathrm{Ti}_{0.5} \mathrm{Mn}_{0.5}$ content, with the $\mathrm{BaFe}_{9}\left(\mathrm{Ti}_{0.5} \mathrm{Mn}_{0.5}\right)_{3} \mathrm{O}_{19}(x=3)$ exhibiting the maximum value of $\mu_{\mathrm{r}}^{\prime \prime}=4.2$. From these results, it may be expected that the electromagnetic wave absorption properties of M-type ferrite may be changed by varying the $\mathrm{Ti}_{0.5} \mathrm{Mn}_{0.5}$ content.

Figure 4 shows the dependence of reflection losses (R.L.) on frequency, for $\mathrm{BaFe}_{12-x}\left(\mathrm{Ti}_{0.5} \mathrm{Mn}_{0.5}\right)_{x} \mathrm{O}_{19}$ sintered ferrites. The matching frequencies $(\mathrm{fm})$ were close to $f r$, and they varied from 15.8 to $3.8 \mathrm{GHz}$, for samples of $x=2.5$ to 5 . The minimum reflection losses for all the samples were less than $-20 \mathrm{~dB}$ at the $\mathrm{fm}$, with the $\mathrm{BaFe}_{7.5}\left(\mathrm{Ti}_{0.5} \mathrm{Mn}_{0.5}\right)_{4.5} \mathrm{O}_{19}$ sample exhibiting the largest $R . L$. of $-41 \mathrm{~dB}$. Therefore, it can be said that these samples were acting as electromagnetic microwave absorbers, in the range 3.8 to $15.8 \mathrm{GHz}$. The matching thicknesses of these M-type ferrite samples varied from 0.5 to $3.8 \mathrm{~mm}$ with increasing $\mathrm{Ti}_{0.5} \mathrm{Mn}_{0.5}$ content. These thicknesses are smaller than for conventional sintered Spinel-type ferrites, which would be an advantage in the production of electromagnetic microwave absorbers.

However, the bandwidths of all the sintered $\mathrm{BaFe}_{12-x}\left(\mathrm{Ti}_{0.5} \mathrm{Mn}_{0.5}\right)_{x} \mathrm{O}_{19}$ ferrites were still too small $(<1$
$\mathrm{GHz}$ ) for use as microwave absorption materials. Therefore, the $\mathrm{BaFe}_{12-x}\left(\mathrm{Ti}_{0.5} \mathrm{Mn}_{0.5}\right)_{x} \mathrm{O}_{19}$ ferrite-resin composites were prepared, by crushing the sintered bodies and mixing with resin. Figure 5 shows the variation of reflection losses (R.L.) vs. frequency, which was observed in composite samples with 60 to 80 mass $\%$ $\mathrm{BaFe}_{9}\left(\mathrm{Ti}_{0.5} \mathrm{Mn}_{0.5}\right)_{3} \mathrm{O}_{19}$ ferrite. The R.L. of the 60 mass $\%$ and 80 mass $\%$ samples were higher than $-20 \mathrm{~dB}$ in the

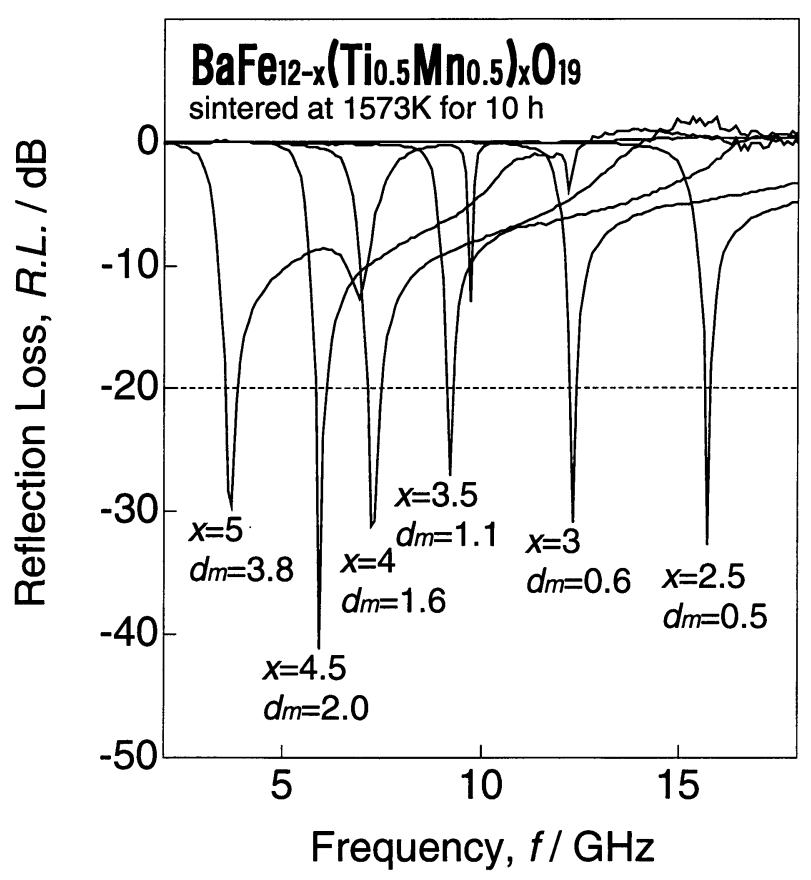

Fig. 4 Dependence of reflection losses (R.L.) on frequency calculated using $\mathrm{BaFe}_{12-x}\left(\mathrm{Ti}_{0.5} \mathrm{Mn}_{0.5}\right)_{x} \mathrm{O}_{19}$ sintered ferrites.

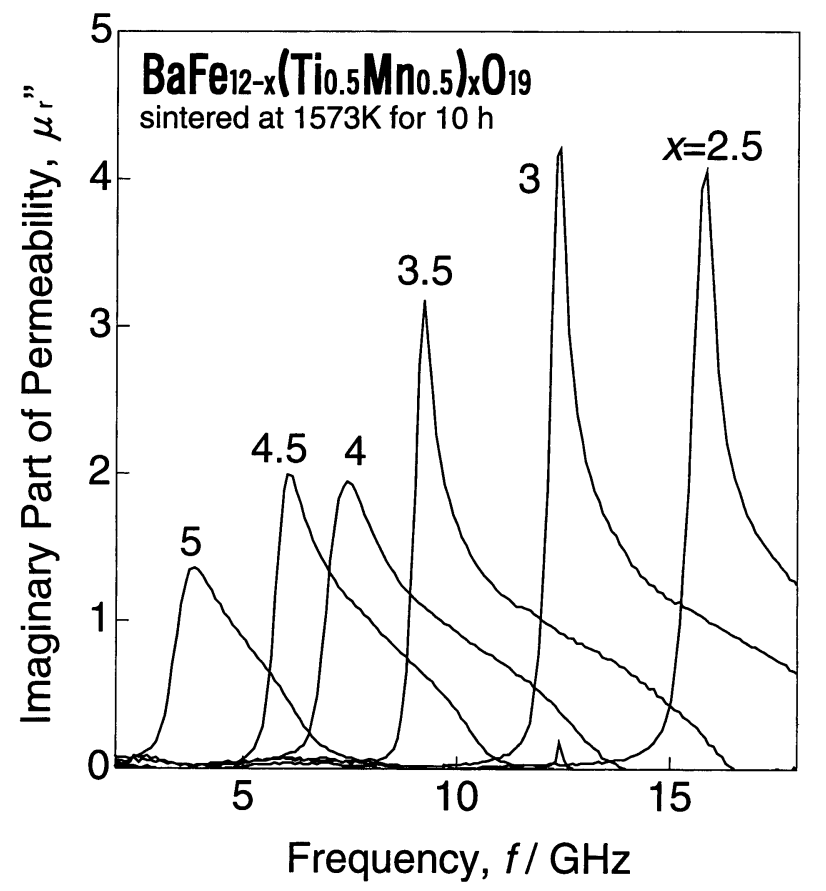

Fig. 3 Dependence of $\mu_{\mathrm{r}}^{\prime \prime}$ values on the frequency measured from sintered $\mathrm{BaFe}_{12-x}\left(\mathrm{Ti}_{0.5} \mathrm{Mn}_{0.5}\right)_{x} \mathrm{O}_{19}$ ferrites with $x=2.5$ to 5 .

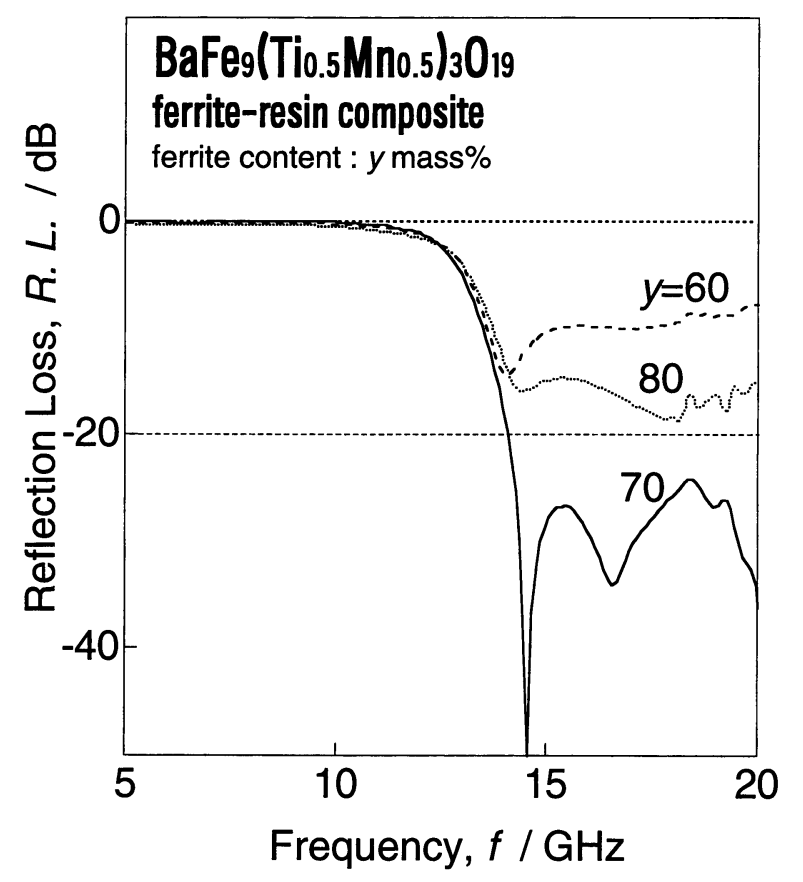

Fig. 5 Dependence of reflection losses (R.L.) on the frequency observed in resin composite materials with $60-80$ mass $\%$ $\mathrm{BaFe}_{9}\left(\mathrm{Ti}_{0.5} \mathrm{Mn}_{0.5}\right)_{3} \mathrm{O}_{19}$ ferrite. 


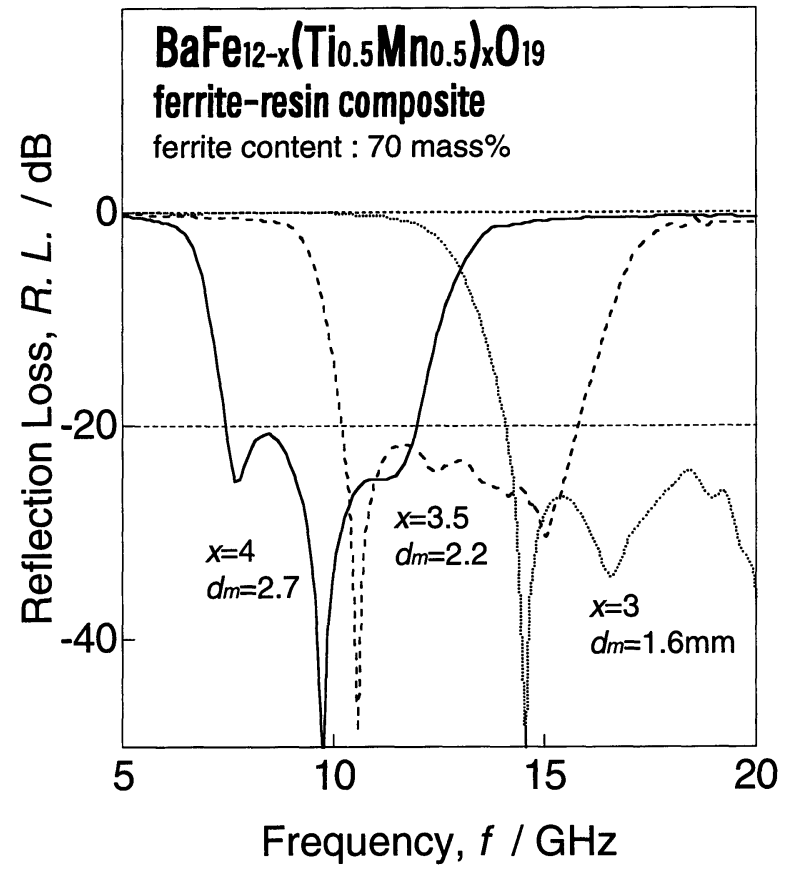

Fig. 6 Variation of R.L. on the frequency of 70 mass $\%$ $\mathrm{BaFe}_{12-x}\left(\mathrm{Ti}_{0.5} \mathrm{Mn}_{0.5}\right)_{x} \mathrm{O}_{19}$ ferrite-resin composites against $\mathrm{Ti}_{0.5} \mathrm{Mn}_{0.5}$ content.

measured frequency range. However, the 70 mass $\%$ sample had a $R$.L. less than $-20 \mathrm{~dB}$ and a wide bandwidth, from $14.1 \mathrm{GHz}$ to greater than $20 \mathrm{GHz}$. The matching thickness $(\mathrm{dm})$ of this sample was $1.6 \mathrm{~mm}$.

Figure 6 shows the dependence of R.L. on the frequency of $\mathrm{BaFe}_{12-x}\left(\mathrm{Ti}_{0.5} \mathrm{Mn}_{0.5}\right)_{x} \mathrm{O}_{19}$-resin composites, whose ferrite content was 70 mass $\%$. The frequency range of $R . L .<-20 \mathrm{~dB}$ shifted to lower frequencies with increasing $\mathrm{Ti}_{0.5} \mathrm{Mn}_{0.5}$ content, which is due to the decrease of the natural resonance frequency as shown in Fig. 2 to 4. The sample with $x=4$ exhibited a R.L. $<-20 \mathrm{~dB}$ in the range 7.4 to $12.0 \mathrm{GHz}$, which covers almost all of the "X-band" frequency range. The matching thickness of this sample was $2.7 \mathrm{~mm}$.

It may be concluded that $\mathrm{BaFe}_{12-x}\left(\mathrm{Ti}_{0.5} \mathrm{Mn}_{0.5}\right)_{x} \mathrm{O}_{19}$ ferrite is a good candidate for use as an electromagnetic microwave absorber in the $\mathrm{GHz}$ range. $\mathrm{BaFe}_{12-x}$ $\left(\mathrm{Ti}_{0.5} \mathrm{Mn}_{0.5}\right)_{x} \mathrm{O}_{19}$ ferrite also has the advantage that the $\mathrm{Fe}_{2} \mathrm{O}_{3}$ content is higher than in conventional spinel ferrites, which may lead to lower production costs.

This is the first study to show that it is possible to use the natural resonance of M-type ferrite to absorb microwave radiation.

\section{Acknowledgment}

The authors would like to thank to Mr. Yoshiaki Maeda, Mr. Kouji Kebukawa, and Mr. Tetsuro Tohma for their help with sample preparations and measurements. This work was partly supported by Grant-in Aid for Scientific Research (No. 09450254), from the Ministry of Education, Science, Sports and Culture of Japan.

\section{REFERENCES}

(1) Y. Kami: J. IEE Japan, 113 (1993), 377.

(2) Y. Naito and K. Suetake: IEEE Trans. Microwave Theory Tech., 19 (1971), 65.

(3) J. L. Snoek: Physica, 8 (1948), 207.

(4) J. Smit and H. P. J. Wijin: Ferrites, Philips Technical Library, Eindohoen, (1959), 208.

(5) J. Nicolas: Ferromagnetic Materials, vol. 2, Chap. 4, ed. by E. P. Wohlfarth, North-Holland Publishing Company, (1980), 243.

(6) H. Kojima: Ferromagnetic Materials, vol. 3, Chap. 5, ed. by E. P. Wohlfarth, North-Holland Publishing Company, (1980), 305.

(7) D. V. Ratnam and W. R. Bussem: IEEE Trans. Magn., MAG-6 (1970), 610

(8) K. Haneda and H. Kojima: Japan J. Appl. Phys., 12 (1973), 355.

(9) D. J. De Bitteto: J. Appl. Phys., 35 (1964), 3482.

(10) K. Okayama, H. Ota, Y. Yoshida, H. Nakamura, T. Kagotani, S. Sugimoto and M. Homma: J. Mag. Soc. Jpn., 22 (1998), 297 (in Japanese).

(11) W. Grünberger, B. Springmann, M. Schmidt and R. Jahnke: J. Magn. Magn. Mater., 101 (1991), 173.

(12) H. M. Musal, Jr. and H. T. Hahn: IEEE Trans. Magn., 25 (1989), 3851. 